\title{
OTIMIZAÇÃO DO CÁLCULO DA CAPACIDADE DE CARGA E TENSÃO ADMISSÍVEL DO SOLO PARA SAPATAS ISOLADAS
}

\section{Optimization of the calculation of the load bearing capacity and allowable stress of the soil for isolated footing}

\author{
Bruna Leal Melo de Oliveira', Luciana Barbosa Amancio²
}

Recebido em 30 de novembro de 2015; recebido para revisão em 28 de fevereiro de 2016; aceito em 30 de maio de 2016; disponivel on-line em 06 de julho de 2016.

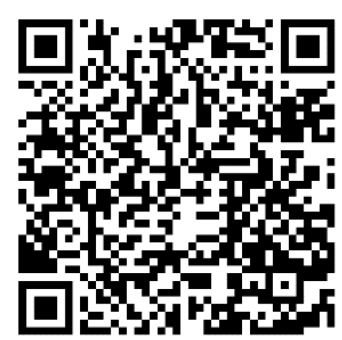

PALAVRAS CHAVE:

Capacidade de carga; Tensão admissível; Automatização.

\section{KEYWORDS:}

Load bearing capacity; Allowable stress; Automation.

\footnotetext{
* Contato com os autores:

${ }^{1}$ e-mail: brunalealmelo@gmail.com (B.L. M. de Oliveira)

Engenheira Civil graduada pela Universidade Federal do Piauí (UFPI).

2e-mail: eng.luciana2009@gmail.com (L. B. Amancio)
}

Professora Mestre do Dep. de Recursos Hídricos, Geotecnia e Saneamento Ambiental Universidade Federal do Piauí (UFPI). testar várias hipóteses para um mesmo problema em um curto período de tempo.

ABSTRACT: For geotechnical design of shallow foundations it is necessary to know the allowable stress of the soil, obtained indirectly from the load bearing capacity; or directly, applying the semi-empirical methods. An alternative to automate these calculations is the use of spreadsheet, a simple tool, aiming to optimize time and reduce human error. To demonstrate the applicability and effectiveness of this tool, a spreadsheet was developed using the Microsoft Excel software, based on some variables such as: cohesion; friction angle; specific weight; groundwater level; among others, to estimate the load bearing capacity and the allowable stress for isolated footing on different occasions, by several methodologies, and in addition, to show graphically the comparison between the results obtained. Finally, the tool was applied on three fictitious scenarios: (1) Square isolated footing with variation of the settlement quota; (2) rectangular isolated footing with variation of the water level and (3) circular isolated footing with execution of the Plate Load Test, proving that it is possible to test several hypotheses for the same problem in a short period of time. 


\section{INTRODUÇÃO}

A NBR 6122 (ABNT, 2010) destaca que a tensão admissível de um solo pode ser encontrada através de três métodos distintos: métodos teóricos; semiempíricos e ensaio de prova de carga sobre placa. Nos métodos teóricos, a capacidade de carga é calculada a partir de formulações propostas por pesquisadores, baseadas na compressibilidade e resistência ao cisalhamento do solo. Já nos métodos semiempíricos os resultados de ensaios de campo, como é o caso da sondagem à percussão SPT, são relacionados diretamente à tensão admissível.

O ensaio de prova de carga sobre placa é utilizado principalmente na aferição dos valores obtidos nos métodos citados anteriormente, uma vez que possibilita plotar a curva tensão-recalque e, a partir da extrapolação desta curva, determinar o valor da capacidade de carga da fundação superficial.

Ao analisar especialmente os métodos teóricos, é fácil notar que determinar manualmente a tensão admissível do solo é um procedimento que acarreta variabilidade nos resultados e demanda bastante tempo. Sendo assim, uma alternativa exequível em tal situação é o uso de ferramentas computacionais práticas e usuais, como é o caso das planilhas eletrônicas, que cresceu bastante na área da engenharia, principalmente, pela necessidade de se otimizar tempo e reduzir falhas de projeto.

Especificamente na engenharia de fundações existem alguns trabalhos publicados nessa linha de pesquisa, como é o caso da rotina computacional apresentada em Cardoso (2011) para dimensionar sapatas de concreto armado, com um ou mais pilares, para um número ilimitado de combinações de ações, e fazer a verificação de segurança para sapatas já existentes.

Em outra pesquisa, Ferreira et al. (2014) desenvolveram um programa para estimar a capacidade de carga em estacas, facilitando a avaliação da melhor metodologia de cálculo, tipo de execução e as possibilidades para os mais variados tipos de estacas. Carvalho (2014) apresentou uma planilha eletrônica para otimizar os custos de projetos de estaqueamento de fundações profundas, com o objetivo de possibilitar a escolha de uma melhor solução relacionada ao custo de projeto de fundações profundas, considerando diversos fatores, tais como: custo unitário das estacas; concreto armado; etc.

\section{OBJETIVO}

Diante da carência de trabalhos publicados sobre ferramentas para o cálculo da capacidade de carga e tensão admissível em sapatas, o presente trabalho tem o objetivo de propor uma planilha eletrônica capaz de automatizar o cálculo da capacidade de carga e da tensão admissível para sapata (quadrada, retangular e circular) com carga vertical centrada por meio de diversas metodologias, considerando a variação do nível freático e os três tipos de rupturas, assim como mostrar graficamente a comparação entre os valores obtidos, e, permitir a análise por profissionais da área, auxiliando-os na tomada de decisões.

\section{METODOLOGIA}

Desenvolveu-se uma planilha eletrônica utilizando-se funções lógicas, aritméticas e gráficos do tipo histogramas comparativos, de modo que, a partir de variáveis relativamente simples, como por exemplo, a coesão, ângulo de atrito, peso específico, nível freático, dimensões da sapata, etc., o usuário terá acesso aos valores da capacidade de carga e da tensão admissível de uma sapata.

Vale ressaltar que esta ferramenta considera: três formatos para as sapatas (quadrada, retangular e circular); a variação do nível freático; e os três tipos de ruptura (generalizada, local e puncionamento), permitindo a aplicação em diferentes cenários, assim como a comparação entre os resultados obtidos.

\subsection{METODOS DE CÁLCULOS}

A primeira etapa no desenvolvimento da planilha eletrônica foi selecionar os métodos empregados, portanto para os teóricos, utilizaram-se as Teorias de Terzaghi (1943), Meyerhof (1963), Brinch-Hansen (1961) e 
Vésic (1975). Para os semiempíricos, foram utilizadas as metodologias propostas por Terzaghi e Peck (1967), Meyerhof (1965) e Teixeira (1996). Já para a prova de carga sobre placa, adotou-se a extrapolação da curva tensão-recalque proposta por Van der Veen (1953).

\subsubsection{Métodos Teóricos}

Os métodos teóricos consistem em formulações clássicas desenvolvidas por estudiosos, como Terzaghi (1943), Meyerhof (1963), BrinchHansen (1961) e Vésic (1975), para estimar a capacidade de carga do solo, e são baseadas essencialmente nas propriedades de resistência ao cisalhamento e na compressibilidade do solo.

Essas formulações estão relacionadas com os mecanismos de ruptura do solo descritos por Vésic (1975), que dependem tanto da rigidez do maciço quanto da cota de assentamento da fundação. O primeiro é a ruptura generalizada, que ocorre em solos mais rígidos, como é o caso de areias compactas e argilas rijas e apresenta superfície de ruptura bem definida. O segundo é o puncionamento, um mecanismo de difícil observação, uma vez que, à medida que a carga aumenta, o solo imediatamente abaixo é comprimido, descendo verticalmente, acompanhando o recalque da fundação. Ocorrem, principalmente, em solos menos rígidos e mais deformáveis, como areais. Por fim, tem-se a ruptura local, tratada como um caso intermediário entre as duas descritas anteriormente. Forma-se uma cunha e superfícies de deslizamento junto à borda da fundação, contudo, essas superfícies não atingem o terreno e não há colapso ou tombamento da fundação. É comum em solos intermediários, como areias medianamente compactas e argilas médias a moles.

Na Tabela 1 encontram-se as expressões desenvolvidas por tais estudiosos para solos com ruptura generalizada e fundações com carga vertical centrada, em que:
$\boldsymbol{\sigma}_{\mathrm{r}}$ : capacidade de carga $(\mathrm{kPa})$;
c: coesão do solo ( $\mathrm{kPa})$;
q: tensão efetiva na cota de apoio ( $\mathrm{kPa})$;
V: peso específico do solo $\left(\mathrm{kN} / \mathrm{m}^{3}\right)$;
B: menor dimensão da fundação $(\mathrm{m})$;
$\mathbf{N}_{\mathbf{c}}, \mathbf{N}_{\mathbf{q}}$ e $\mathbf{N}_{\boldsymbol{\gamma}}$ : fatores de capacidade de carga;

$\mathbf{s}_{\mathbf{c}}, \mathbf{s}_{\mathbf{q}}$ e $\mathbf{s}_{\boldsymbol{\gamma}}$ : fatores de forma;
$\mathbf{d}_{\mathbf{c}}, \mathbf{d}_{\mathbf{q}}$ e $\mathbf{d}_{\boldsymbol{\gamma}}$ : fatores de profundidade.

Na Tabela 2 encontram-se as formulações para o cálculo dos fatores de capacidade, forma e profundidade para cada um desses autores, sendo que:

$$
\mathrm{K}_{\mathrm{py}}=\tan ^{2}\left(45+\frac{\phi}{2}\right) \quad \text { Eq. [1] }
$$

L: maior dimensão da sapata $(\mathrm{m})$;

h: cota de assentamento da fundação (m);

k: coeficiente dado por:

$$
\begin{aligned}
& k=\frac{h}{B}, \operatorname{para} \frac{h}{B} \leq 1 \\
& k=\arctan \left(\frac{h}{B}\right), \operatorname{para} \frac{h}{B}>1
\end{aligned}
$$

TABELA 1: Expressões da capacidade de carga para sapatas isoladas com carga vertical centrada.

Autor

Formulação

\begin{tabular}{cl}
\hline Terzaghi (1943) & $\sigma_{r}=c N_{c}+q N_{q}+0,5 \gamma B N_{\gamma}$ \\
\hline Meyerhof (1963) & $\sigma_{r}=c N_{c} s_{c} d_{c}+q N_{q} s_{q} d_{q}+0,5 \gamma B N_{\gamma} s_{\gamma} d_{\gamma}$ \\
\hline Brinch-Hansen (1961) & $\sigma_{r}=c N_{c} s_{c} d_{c}+q N_{q} s_{q} d_{q}+0,5 \gamma B N_{\gamma} s_{\gamma} d_{\gamma}$ \\
\hline Vesic (1975) & $\sigma_{r}=c N_{c} s_{c} d_{c}+q N_{q} s_{q} d_{q}+0,5 \gamma B N_{\gamma} s_{\gamma} d_{\gamma}$
\end{tabular}


TABELA 2: Fatores de cálculo da capacidade de carga para os métodos teóricos.

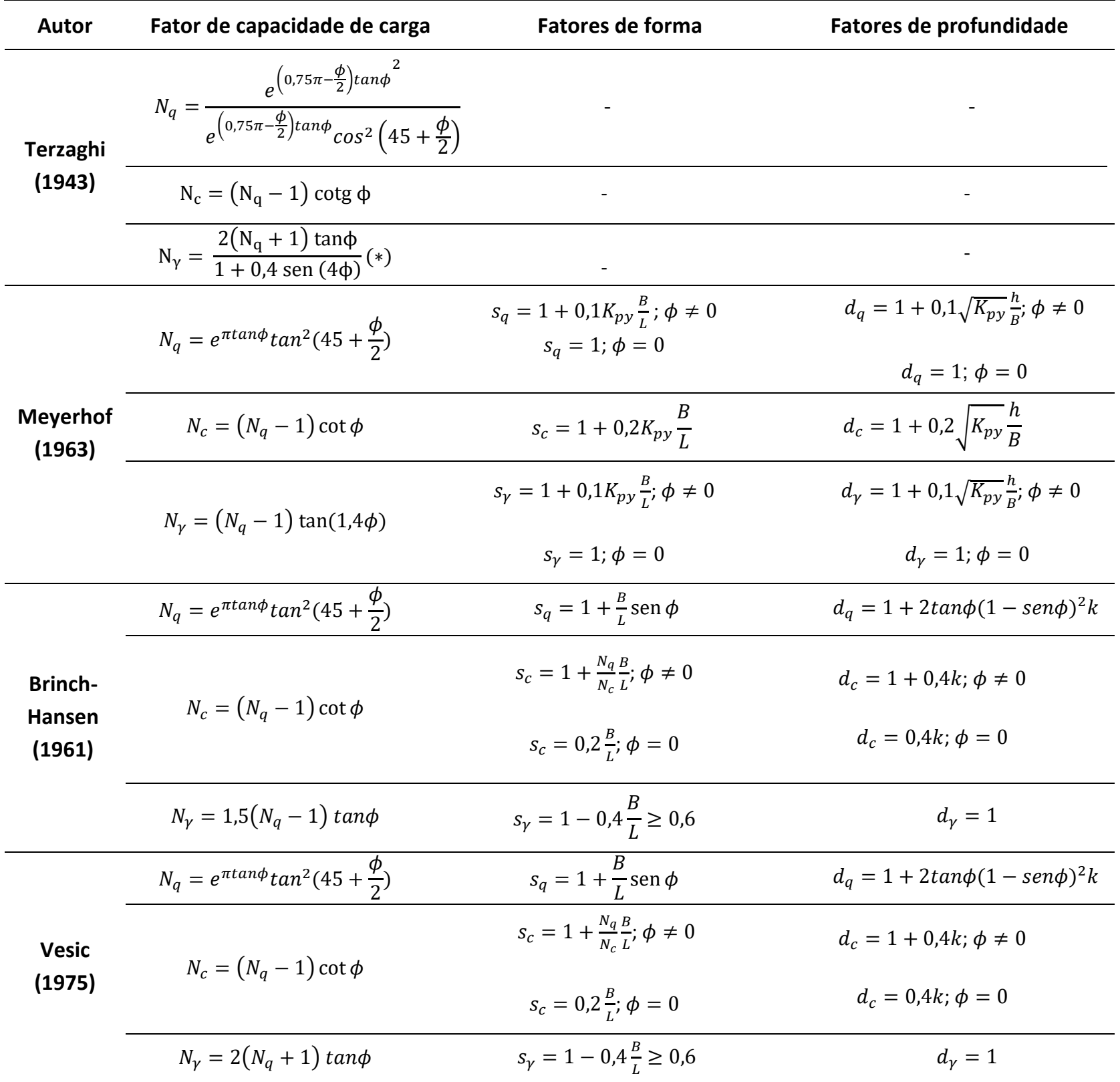

Admitindo-se que o mecanismo de ruptura em solos fofos e moles ocorre por puncionamento, para tanto, Terzaghi (1943) propôs a utilização da mesma equação usada para ruptura generalizada, porém, emprega uma redução empírica na coesão do solo, em kPa, e no ângulo de atrito, em graus, conforme as seguintes equações:

$$
\begin{array}{cc}
c^{\prime}=\frac{2}{3} c & \text { Eq. [4] } \\
\tan \phi^{\prime}=\frac{2}{3} \tan \phi & \text { Eq. [5] } \\
\text { Já no caso em que o solo apresenta }
\end{array}
$$
mecanismo de ruptura local, Cintra et al. (2011) sugerem calcular o valor médio da capacidade de carga para as condições de ruptura geral e de puncionamento para todos os métodos teóricos.

Além do mecanismo de ruptura, a variação no nível d'água influencia o cálculo da capacidade de carga, conforme a Figura 1. Nota-se que há três possibilidades:

a) O nível do lençol freático acima da base da fundação;

b) O nível do lençol freático coincide com a base da fundação;

c) O nível do lençol freático abaixo da base da fundação. 


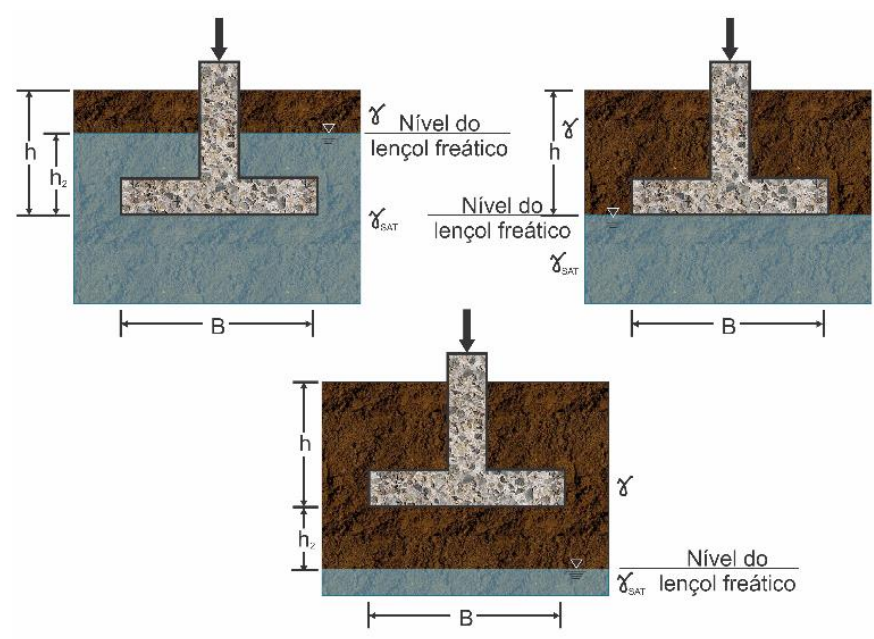

FIGURA 1: Influência do lençol freático. FONTE: Adaptado de DAS (2007).

Para cada um desses casos, Das (2007) recomenda efetuar as correções tanto no cálculo da pressão efetiva como no peso específico do solo, conforme mostra a Tabela 3, em que:

$\boldsymbol{\gamma}$ : peso específico do solo seco $\left(\mathrm{kN} / \mathrm{m}^{3}\right)$;

$\boldsymbol{\gamma}_{\text {sat }}$ : peso específico do solo saturado abaixo do $\mathrm{NA}\left(\mathrm{kN} / \mathrm{m}^{3}\right)$;

$\boldsymbol{\gamma}_{\mathbf{a}}$ : peso específico da água $\left(\mathrm{kN} / \mathrm{m}^{3}\right)$;

$\boldsymbol{h}_{\mathbf{1}}$ : profundidade do lençol freático em relação à superfície do terreno $(\mathrm{m})$;

$\boldsymbol{h}_{\mathbf{2}}$ : distância vertical do lençol freático à base do elemento de fundação $(\mathrm{m})$.

Analisando as expressões apresentadas anteriormente, percebe-se que as variáveis independentes são: coesão; ângulo de atrito; peso específico do solo (seco e saturado); nível do lençol freático; dimensões da fundação e cota de assentamento, por isso foram adotadas como variáveis de entrada para os métodos teóricos, sendo as demais calculadas automaticamente pela planilha. É importante lembrar que essas informações podem ser obtidas através de

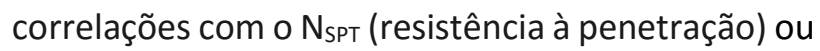
através de ensaios realizados em campo e/ou laboratório.
Portanto, quando o usuário digita as variáveis de entrada, é calculado o valor da capacidade de carga para cada método, considerando o formato da base (retangular, quadrada ou circular), o tipo de mecanismo de ruptura (generalizada, puncionamento ou local) e as correções sugeridas por Das (2007) para o nível freático. Além disso, para determinar a tensão admissível, optou-se por utilizar a recomendação da NBR 6122 (ABNT, 2010) aplicando-se um fator de segurança igual a 3 (três), sendo que esse valor pode ser editado na ferramenta.

\subsubsection{Métodos Semiempíricos}

Os métodos semiempíricos foram inseridos na planilha para permitir a comparação com o valor da tensão admissível obtido no ensaio de placa, descrito no próximo subitem (3.1.3). Dentre eles, destacam-se: Terzaghi e Peck (1967); Meyerhof (1965) e Teixeira (1996).

A Tabela 4 resume as formulações para cada autor, onde se nota que as expressões apresentam como variáveis os valores obtidos na sondagem SPT ( $\left.\mathrm{N}_{\mathrm{SPT}}\right)$, a menor dimensão da sapata (no caso do formato circular, o diâmetro) e o recalque admissível. Por se tratar de informações adquiridas diretamente, ou seja, não são determinadas por meio de equações, foram adotadas como variáveis de entrada para os métodos semiempíricos e a tensão admissível é calculada automaticamente pela planilha.

Isso implica que, se o usuário possui o relatório de uma sondagem e os dados de um ensaio de prova de carga sobre placa, a ferramenta exibirá um gráfico do tipo histograma, comparando cada uma das metodologias empregadas com a tensão admissível determinada a partir da curva cargarecalque do ensaio de placa.

TABELA 3: Alterações no cálculo da capacidade de carga devido à influência do nível d'água.

\begin{tabular}{ccc} 
& Pressão efetiva (q) & Peso específico $(\gamma)$ \\
\hline Caso (a) & $q=\gamma h_{1}+\left(\gamma_{s a t}-\gamma_{a}\right) h_{2}$ & $\gamma^{\prime}=\gamma_{s a t}-\gamma_{a}$ \\
\hline Caso (b) & - & $\gamma^{\prime}=\gamma_{s a t}-\gamma_{a}$ \\
\hline Caso (c) & - & $\gamma_{\text {med }}=\left(\gamma_{s a t}-\gamma_{a}\right)+\frac{h_{2}}{B}\left(\gamma-\gamma_{s a t}+\gamma_{a}\right)$ \\
\hline
\end{tabular}


TABELA 4: Formulações para os métodos semiempíricos.

\begin{tabular}{lc}
\multicolumn{1}{c}{ Autor } & Formulação \\
\hline Terzaghi e Peck (1967) & $\sigma_{\mathrm{adm}}=440\left(\frac{\mathrm{N}_{\mathrm{SPT}}-3}{10}\right)\left(\frac{\mathrm{B}+1}{2 \mathrm{~B}}\right)$ \\
\hline Meyerhof (1965) & $\sigma_{a d m}=\frac{10 \cdot N_{S P T} \cdot \rho_{a d m}}{12}\left(\frac{B+1}{B}\right)^{2}$ \\
\hline Teixeira (1996) & $\sigma_{a d m}=50+(1+0,4 B) 10 N_{S P T}$
\end{tabular}

FONTE: adaptada de Noguchi (2012).

Em que:

$\sigma_{\boldsymbol{a d m}}$ : tensão admissível $(\mathrm{kPa})$;

$\boldsymbol{\rho}_{\boldsymbol{a d m}}$ : recalque admissível $(\mathrm{mm})$;

B: menor dimensão da sapata $(\mathrm{m})$;

$\mathbf{N}_{\text {SPT }}$ : número de golpes obtidos no ensaio

SPT.

\subsubsection{Ensaio de Placa}

O ensaio de prova de carga sobre placa, segundo Hachich et al. (1998), constitui-se de um modelo reduzido de uma sapata, realizado em campo, para analisar o comportamento tensãodeformação do sistema sapata-solo. Durante o ensaio, os recalques provocados pelas tensões são medidos por extensômetros, e, de posse desses valores, é possível traçar a curva tensão-recalque, conforme ilustra a Figura 2, a partir da qual se pode estimar a capacidade de carga do solo, o recalque da fundação e as características de ruptura, deformabilidade e resistência da mesma.

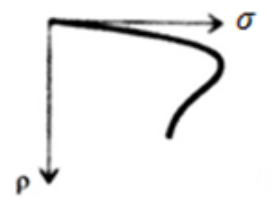

(a)

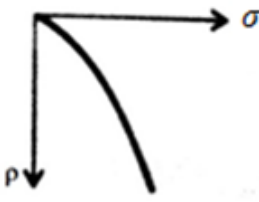

(b)

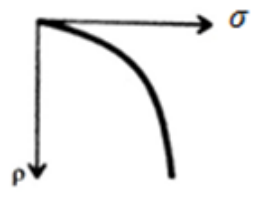

(c)
FIGURA 2: Curva tensão-recalque para a) ruptura generalizada, b) ruptura por puncionamento, c) ruptura local.

FONTE: VELLOSO E LOPES (2010).

Observa-se na Figura 2a que os solos com ruptura generalizada apresentam a tensão de ruptura bem definida. No entanto, para solos com ruptura por puncionamento e local não é possível detectar esta tensão somente pelo comportamento da curva. Constatando-se esse fato, surge a necessidade de aplicar metodologias, sendo a mais usual aquela proposta por Van der Veen (1953), para a extrapolação da curva tensão-recalque. Van der Veen define a tensão aplicada através da seguinte expressão:

$$
\sigma_{S}=\sigma_{R}\left(1-e^{-\rho}\right)
$$

Em que:

$\sigma_{\boldsymbol{s}}$ : tensão aplicada ( $\left.\mathrm{kPa}\right) ;$

$\sigma_{R}$ : tensão de ruptura ou capacidade de carga (kPa);

$$
\text { p: recalque }(\mathrm{mm}) \text {. }
$$

A partir dessa expressão, deduz-se que existe uma relação linear entre o recalque, $\rho$, e o valor $\ln \left(1-\frac{\sigma_{\mathrm{s}}}{\sigma_{R}}\right)$. Dessa forma, determina-se a capacidade de carga efetuando-se tentativas com diferentes valores de $\sigma_{R}$ e plotando-se uma curva $\ln \left(1-\frac{\sigma_{\mathrm{s}}}{\sigma_{R}}\right)$ versus recalque para cada valor estimado. A capacidade de carga será àquele valor que corresponde a uma curva com coeficiente de determinação $\left(R^{2}\right)$ aproximadamente igual a 1,0.

Após encontrar $o$ valor de $\sigma_{R}$, que corresponde à capacidade de carga do solo, a NBR 6122 (ABNT, 2010) propõe dividi-lo por um coeficiente de segurança igual a 2,0 para obter a tensão admissível.

\section{APRESENTAÇÃO DA PLANILHA ELETRÔNICA}

A página inicial, mostrada na Figura 3, possui cinco opções: tutorial, que descreve como usar a ferramenta; métodos teóricos; métodos semiempíricos; prova de carga sobre placa; e gráficos. Ao colocar em qualquer uma das opções, o usuário é direcionado à aba correspondente. 
A aba "métodos teóricos", conforme ilustra a Figura 4, está dividida em quatro itens: dados de entrada, tipos de ruptura, capacidade de carga e tensão admissível.

As células na cor branca são preenchidas pelo usuário, e as células amarelas correspondem aos resultados. Ao digitar as dimensões da sapata, o programa identifica o formato da mesma (retangular - R, quadrada - Q ou circular - C), tendo em vista que as fórmulas da capacidade de carga são condicionadas ao formato do elemento.

Para definir o tipo de ruptura, fez-se a reprodução do gráfico (Figura 5) proposto por Cintra et al. (2011) em função do ângulo de atrito e da coesão do maciço. Vésic (1975) reconhece que existem três mecanismos de ruptura do solo: ruptura generalizada, por puncionamento e local, conforme ilustra a Figura 6.

\section{PREVISÃ० DE OAPAOIDAPE DE OARGด E TEnsÃ॰ apmIssívEL paRa sapaTas}

ALUNA:

BRUNA LEAL MELO DE OLIVEIRA

brunalealmelo@gmail.com
PROFESSORA ORIENTADORA:

LUCIANA BARBOSA AMANCIO eng.luciana2009@gmail.com

\section{TUTORIคL}

\section{mÉTOPOS TEÓRIOOS}

\section{semiempírioos}

\section{PROYA DE OnRG}

\section{Gráfloos}

FIGURA 3: Interface da página inicial da planilha eletrônica.

FONTE: Elaborada pelas autoras (2015).

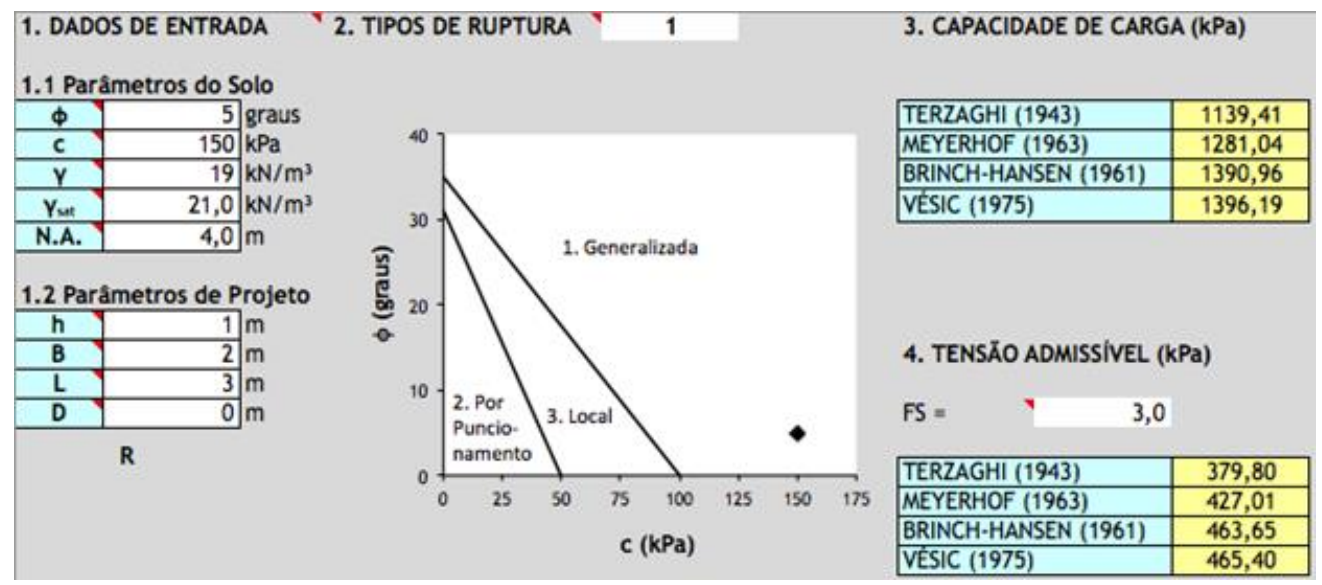

FIGURA 4: Interface da planilha eletrônica para os métodos teóricos. FONTE: Elaborada pelas autoras (2015). 


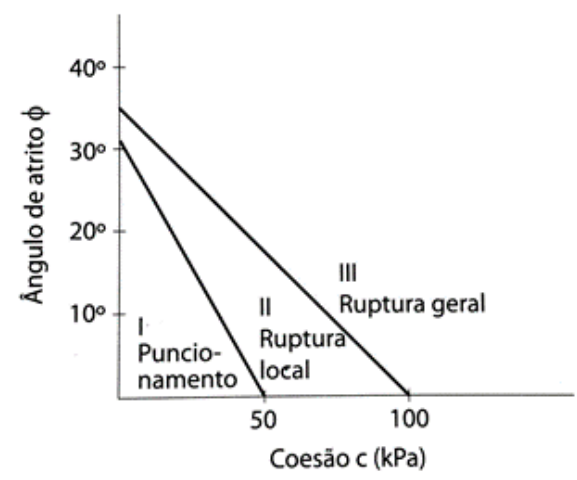

FIGURA 5: Gráfico dos mecanismos de ruptura do solo.

FONTE: Cintra et al. (2011).

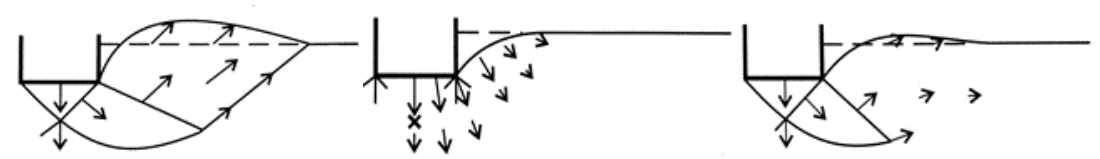

(a)

(b)

(c)

FIGURA 6: (a) Ruptura Generalizada (b) Ruptura por puncionamento (c) Ruptura local.

FONTE: Velloso e Lopes (2010).

Após inserir os valores da coesão e do ângulo de atrito do solo, será apontado no gráfico, automaticamente, o tipo de ruptura (1generalizada, 2-por puncionamento, 3-local), e esta informação deve ser digitada pelo usuário na célula de cor branca indicada.

Com base no formato da base da fundação, no tipo de ruptura e na cota do nível d'água, os resultados da capacidade de carga e da tensão admissível são calculados automaticamente. Vale ressaltar que o fator de segurança da tensão admissível fica a critério do usuário.

$\mathrm{Na}$ aba "métodos semiempíricos" (Figura 7), os dados de entrada necessários são baseados nas teorias escolhidas: $\mathrm{N}_{\mathrm{SPT}}$, dimensões da sapata e recalque admissível. Após inseridos os dados, a planilha identifica a forma do elemento e calcula a tensão admissível.

Em relação à aba prova de carga sobre placa (Figura 8), foi desenvolvida uma tabela para informar as tensões $(\sigma)$ e recalques $(\rho)$ obtidos no ensaio. A partir desses dados, a curva tensão x recalque é plotada.

Com a finalidade de aplicar o método de Van der Veen (1953) para extrapolar esta curva, elaborou-se outra tabela para inserir os valores arbitrários da tensão de ruptura $\left(\sigma_{\mathrm{R}}\right)$, e, através da Equação 6, calcular os recalques para as mesmas tensões aplicadas no ensaio.

De posse dos valores desta tabela, é plotado o gráfico "Método de Van Der Veen (1953)", onde constam as linhas de tendência lineares correspondentes a cada valor de $\sigma_{R}$. Portanto, o usuário deve optar pela tensão de ruptura que corresponde ao $\mathrm{R}^{2}$ mais próximo de 1,0 , digitar 0 valor na célula correspondente e, posteriormente, a tensão admissível do solo é exibida.

Por último, foram confeccionados três histogramas: capacidade de carga (métodos teóricos $\mathrm{x}$ prova de carga); tensão admissível (métodos teóricos $\mathrm{x}$ prova de carga); tensão admissível (métodos semiempíricos $x$ prova de carga), auxiliando o usuário na análise dos resultados, conforme ilustra a Figura 9.

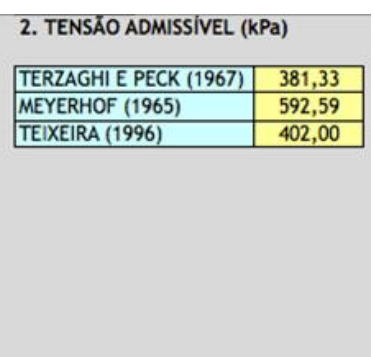

FIGURA 7: Interface da planilha eletrônica para os métodos semiempíricos. FONTE: Elaborada pelas autoras (2015). 

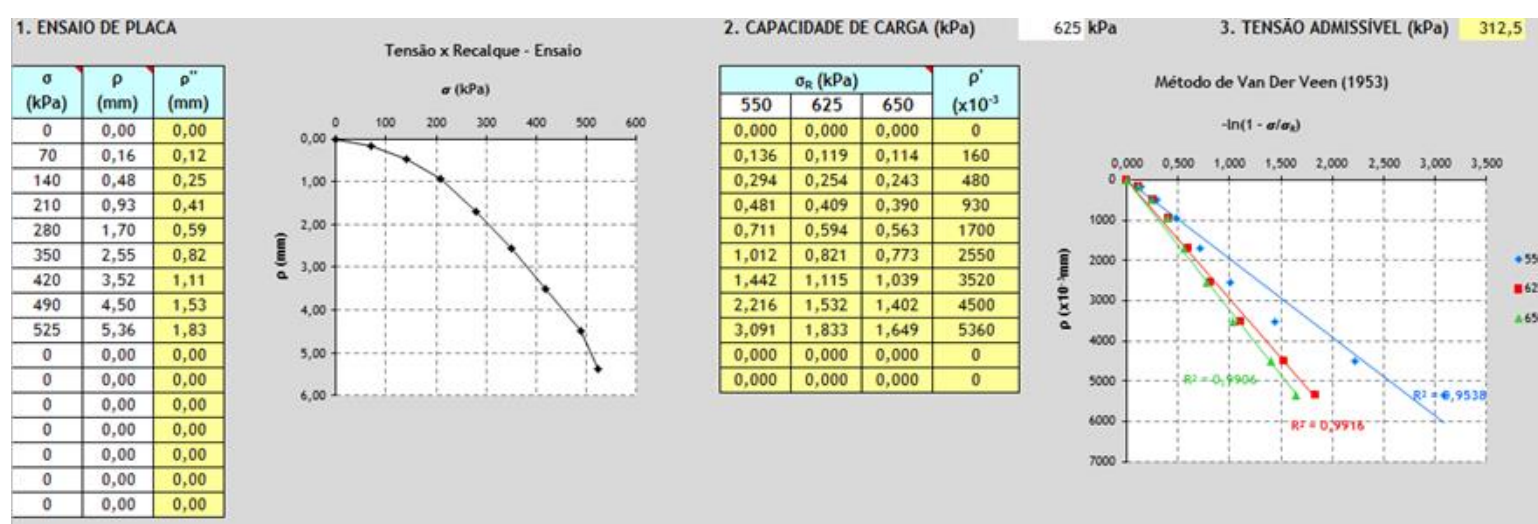

FIGURA 8: Interface da planilha para prova de carga sobre placa.

FONTE: Elaborada pelas autoras (2015).
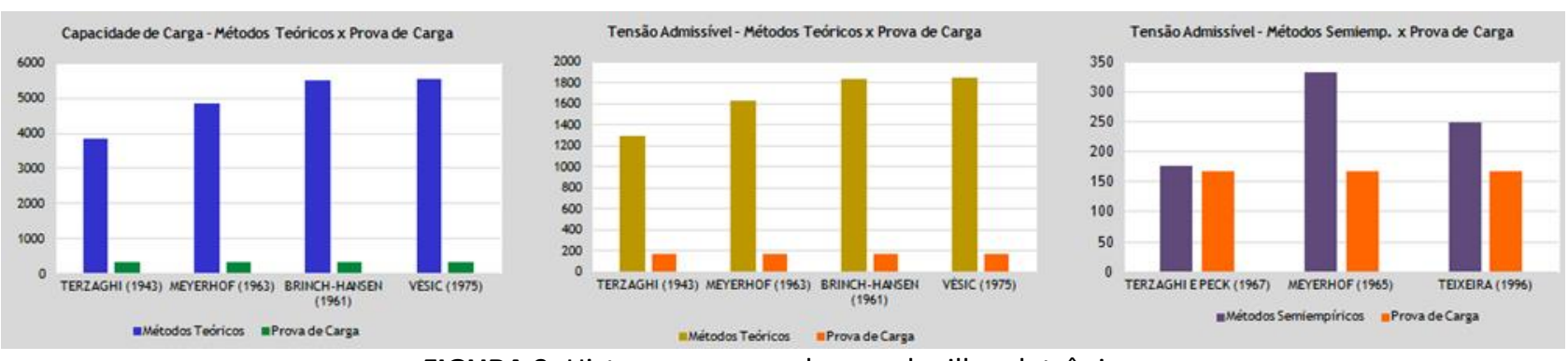

FIGURA 9: Histogramas gerados na planilha eletrônica.

FONTE: Elaborada pelas autoras (2015).

\section{RESULTADOS E DISCUSSÕES}

Com o intuito de demonstrar a aplicabilidade da ferramenta proposta, foram resolvidos três cenários fictícios distintos, que estão detalhados a seguir.

a) Cenário 1 - variação da cota de assentamento.

Neste cenário foi utilizada uma sondagem realizada na cidade de Teresina/PI, ilustrada na Figura 10, onde se nota que o nível d'água encontrase a 2,7 m. Optou-se por uma sapata de base quadrada 3,0 × 3,0 m assentada a 4,0 m de profundidade, na camada de argila siltosa e, para analisar a influência da variação da cota de assentamento nos valores da tensão admissível do solo, admitiram-se três hipóteses: h igual a 3; 4 e 5 $\mathrm{m}$ medidos a partir da superfície do terreno.

Os parâmetros do solo como: coesão, ângulo de atrito, peso específico natural e saturado, foram obtidos a partir de correlações com o valor médio do $\mathrm{N}_{\text {SPT. }}$. Os valores obtidos com a planilha para a capacidade de carga e a tensão admissível estão resumidos na Tabelas 5.
Observa-se que os métodos se comportam de maneira semelhante quanto às variações da cota de assentamento, uma vez que os valores da tensão admissível aumentam à medida que a cota de assentamento se aproxima da camada impenetrável. Nota-se que as variações são pequenas, podendo-se afirmar que para esse caso 0 efeito da mudança da cota de assentamento para a tensão admissível foi insignificante.

Com a finalidade de facilitar a visualização destes resultados, elaborou-se o gráfico tensão admissível $\mathrm{x}$ cota de assentamento, como mostra a Figura 11. Percebe-se que para o método de Meyerhof (1963) houve um aumento de aproximadamente $8 \%$ tanto para a alteração de 3,0 $\mathrm{m}$ para $4 \mathrm{~m}$ de profundidade quanto de $4,0 \mathrm{~m}$ para 5,0 m. Isso pode ser explicado devido ao do fator de profundidade $\left(\mathrm{s}_{\mathrm{q}}\right)$ proposto por Meyerhof variar à medida que a cota aumenta, enquanto que este mesmo fator mantém-se constante para as demais metodologias.

A ferramenta também fornece os valores da tensão admissível para os métodos semiempíricos, conforme a Tabela 6, e com isso permite a comparação destes com os valores dos métodos teóricos. 


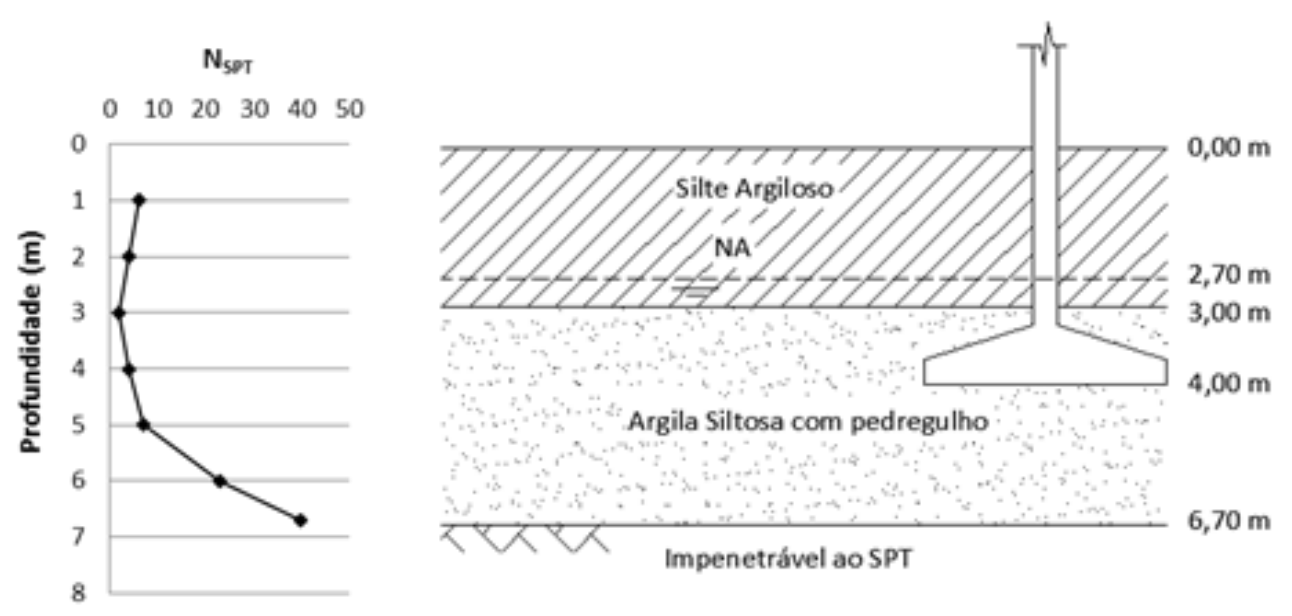

FIGURA 10: Sondagem à percussão para cenário 1.

FONTE: Elaborada pelas autoras (2015).

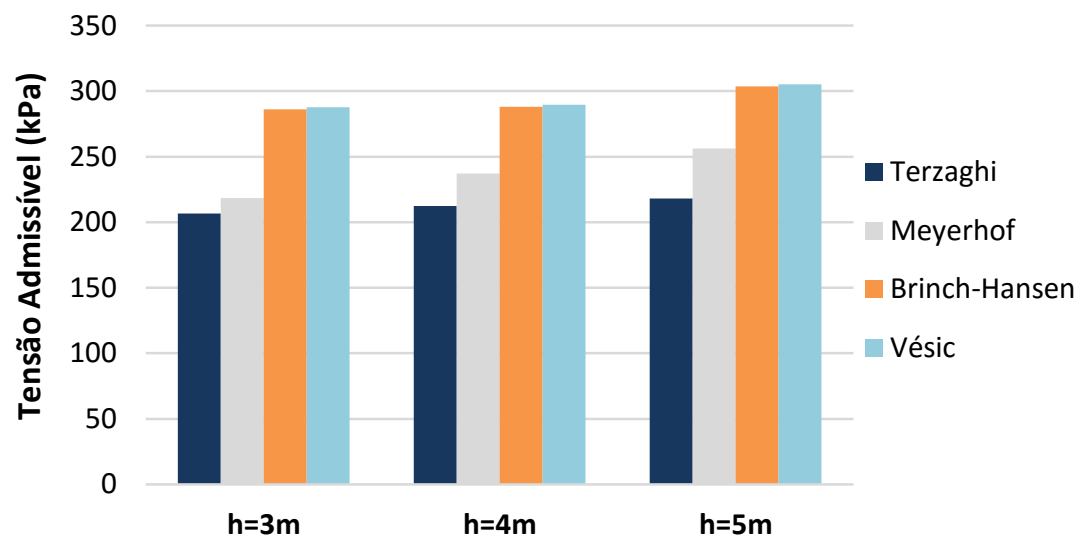

FIGURA 11: Tensão admissível $x$ cota de assentamento.

FONTE: Elaborada pelas autoras (2015).

TABELA 5: Capacidade de carga pelos métodos teóricos para o cenário 1, em kPa.

\begin{tabular}{lcccccc} 
& \multicolumn{3}{c}{ Capacidade de Carga } & \multicolumn{3}{c}{ Tensão Admissível } \\
\hline & $\mathbf{h = 3 , 0} \mathbf{m}$ & $\mathbf{h = 4 , 0} \mathbf{m}$ & $\mathbf{h = 5 , 0} \mathbf{m}$ & $\mathbf{h = 3 , 0} \mathbf{m}$ & $\mathbf{h = 4 , 0} \mathbf{~}$ & $\mathbf{h = 5 , 0} \mathbf{~}$ \\
\hline Terzaghi (1943) & 619,68 & 636,96 & 654,24 & 206,56 & 212,32 & 218,08 \\
\hline Meyerhof (1963) & 655,59 & 711,67 & 768,97 & 218,56 & 237,22 & 256,32 \\
\hline Brinch-Hansen (1961) & 858,64 & 864,28 & 911,00 & 286,21 & 288,09 & 303,67 \\
\hline Vésic (1975) & 863,38 & 869,02 & 915,74 & 287,79 & 289,67 & 305,25 \\
\hline & & & & FONTE: elaborada pelas autoras (2015).
\end{tabular}

TABELA 6: Tensão admissível pelos métodos semiempíricos para o cenário 1, em kPa.

\begin{tabular}{cccc} 
& $\mathbf{h = 3 , 0 ~} \mathbf{m}$ & $\mathbf{h = 4 , 0 ~} \mathbf{~}$ & $\mathbf{h = 5 , 0 ~} \mathbf{~}$ \\
\hline Terzaghi e Peck (1943) & 176,00 & 234,67 & 352,00 \\
\hline Meyerhof (1965) & 333,33 & 407,41 & 555,56 \\
\hline Teixeira (1996) & 248,00 & 292,00 & 380,00 \\
\hline
\end{tabular}

FONTE: elaborada pelas autoras (2015). 
Observa-se que para os métodos semiempíricos as variações com a mudança na cota de assentamento, entre os valores das tensões admissíveis, são maiores do que para os métodos teóricos, uma vez que para aplicar os métodos teóricos é necessário admitir o solo como sendo homogêneo. Além disso, a diferença entre os valores das tensões admissíveis entre os métodos teóricos e os semiempíricos é pequena. É fácil também perceber que os valores para Meyerhof (1965) são maiores enquanto para Terzaghi e Peck (1943) e Teixeira (1996) são muito próximos.

b) Cenário 2 - variação do nível d'água

Para o cenário 2 foi utilizada uma sondagem executada na cidade de Timon/MA, conforme mostra a Figura 12. Neste caso, a sapata apresenta base retangular 4,0 × 3,0 m e está assentada no topo da camada de areia fina siltosa. Inicialmente o nível d'água encontra-se a 2,0 m abaixo da superfície do terreno, e como se pretende avaliar as alterações das tensões admissíveis ocasionadas pela variação do nível d'água, adotaram-se três hipóteses: NA igual a 2,0; 4,0 e 6,0 m medidos a partir da superfície do terreno.
Repetiu-se o mesmo procedimento do cenário 1 para adquirir os parâmetros do solo, e os valores da capacidade de carga e a tensão admissível para os métodos teóricos, que são os únicos que consideram as alterações do nível d'água, estão resumidos na Tabelas 7 .

Observa-se que os métodos se comportam de maneira semelhante quanto às variações do nível d'água, uma vez que os valores da tensão admissível aumentam à medida que o nível d'água se distancia da cota de assentamento, saindo do bulbo das tensões.

Com o intuito de melhorar a visualização destes resultados, elaborou-se o gráfico tensão admissível x nível d'água, ilustrado na Figura 13. Nota-se que o método de Meyerhof apresenta a maior variação, ou seja, 41,1 e 48\%, quando o nível da água baixou para 4,0 e 6,0 m, respectivamente.

Através dessa análise é perceptível que a presença de água próxima à cota de assentamento da sapata reduz a tensão admissível do solo, podendo ocasionar danos irreversíveis às fundações, caso essa alteração não seja considerada pelos projetistas durante o dimensionamento.

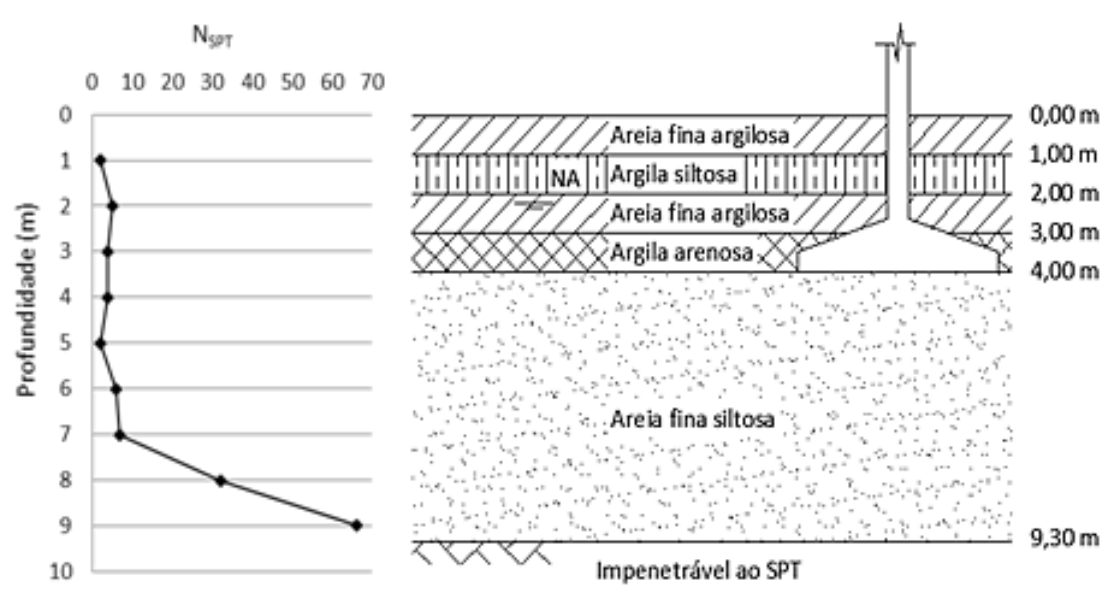

FIGURA 12: Sondagem à percussão para cenário 2. FONTE: Elaborada pelas autoras (2015).

TABELA 7: Capacidade de carga e tensão admissível pelos métodos teóricos para o cenário 2, em kPa.

\begin{tabular}{lcccccc} 
& \multicolumn{3}{c}{ Capacidade de Carga } & \multicolumn{3}{c}{ Tensão Admissível } \\
\hline & NA = 2,0 $\mathbf{m}$ & NA = 4,0 $\mathbf{m}$ & NA = 6,0 m & NA = 2,0 m & NA = 4,0 m & NA = 6,0 m \\
\hline Terzaghi (1943) & 484,70 & 601,03 & 636,92 & 161,57 & 200,34 & 212,31 \\
\hline Meyerhof (1963) & 478,19 & 674,79 & 707,30 & 159,40 & 224,93 & 235,77 \\
\hline Brinch-Hansen (1961) & 678,29 & 841,62 & 890,85 & 226,10 & 280,54 & 296,95 \\
\hline Vésic (1975) & 733,34 & 899,15 & 972,33 & 244,45 & 299,72 & 324,11 \\
\hline
\end{tabular}

FONTE: elaborada pelas autoras (2015). 


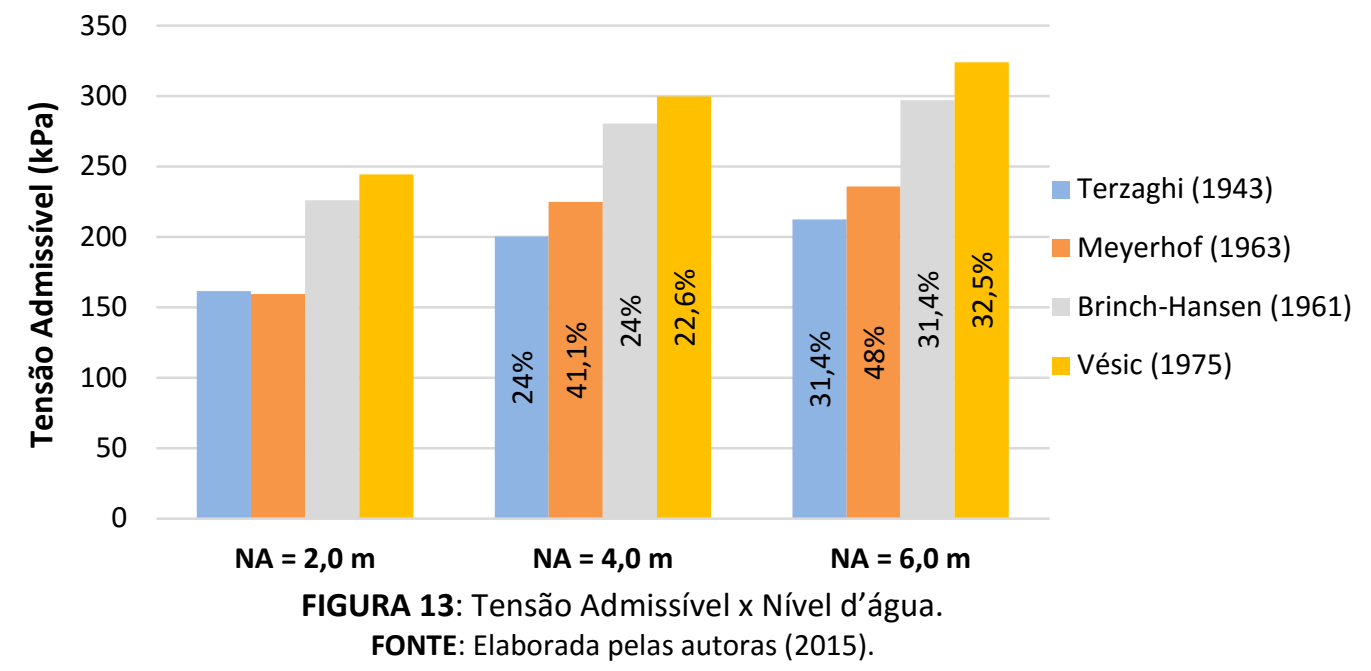

c) Cenário 3 - prova de carga sobre placa

Neste cenário utilizaram-se os resultados obtidos por Medeiros (2013) em um ensaio de placa e uma sondagem SPT realizados na cidade de Fortaleza/CE. Deste modo, a sapata adotada terá base circular com diâmetro igual a 0,80 m assentada a 1,5m em relação a superfície do terreno. Observam-se os resultados da sondagem na Figura 14.

Os parâmetros do solo obtidos a partir da sondagem foram inseridos na planilha que forneceu a informação de uma ruptura por puncionamento. Na Tabela 8, encontram-se os resultados da capacidade de carga e da tensão admissível do solo, respectivamente, para os métodos teóricos.

Nota-se que, tanto para a capacidade de carga como para a tensão admissível, os valores máximos e mínimos correspondem, respectivamente, aos métodos de Vésic (1975) e
Terzaghi (1943), sendo a diferença igual a 58\%. Essa diferença pode ser explicada pelos fatores de correções inseridos por Vésic nas formulações.

Na Tabela 9 estão os valores da tensão admissível para os métodos semiempíricos, onde se constata que o método de Teixeira (1996), embora desenvolvido para solos arenosos, apresentou um valor superior aos demais.

De posse dos valores medidos durante o ensaio de prova de carga sobre placa, a planilha fornece a curva tensão-recalque ilustrada na Figura 15.

Observa-se que a ruptura ocorre para valores maiores de $300 \mathrm{kPa}$. À vista disso, foram estipulados alguns valores para a tensão de ruptura, até alcançar $R^{2}$ igual a 0,9788, o mais próximo de 1,0 encontrado, que corresponde a uma tensão de ruptura igual a 335 kPa. Seguindo a NBR 6122 (ABNT, 2010), a tensão admissível do solo é $167,5 \mathrm{kPa}$.

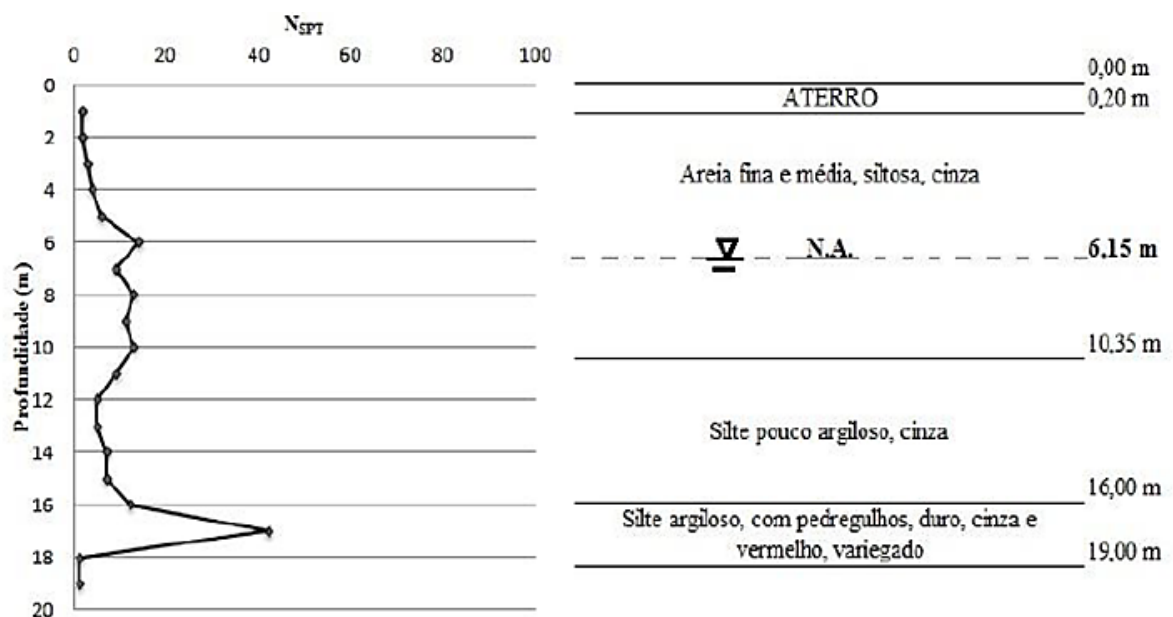

FIGURA 14: Sondagem à percussão para cenário 3. FONTE: Elaborada pelas autoras (2015). 
TABELA 8: Capacidade de carga e tensão admissível pelos métodos teóricos para o cenário 3, em kPa.

\begin{tabular}{lcc} 
& Capacidade de carga & Tensão admissível \\
\hline Terzaghi (1943) & 145,97 & 48,66 \\
\hline Meyerhof (1963) & 185,81 & 61,94 \\
\hline Brinch-Hansen (1961) & 220,39 & 73,46 \\
\hline Vésic (1975) & 230,93 & 76,98 \\
\hline
\end{tabular}

FONTE: Elaborada pelas autoras (2015).

TABELA 9: Tensão admissível pelos métodos semiempíricos para o cenário 3, em kPa.

\begin{tabular}{cc} 
Terzaghi e Peck (1967) & 49,50 \\
\hline Meyerhof (1965) & 35,05 \\
\hline Teixeira (1996) & 102,80 \\
\hline
\end{tabular}

FONTE: Elaborada pelas autoras (2015).

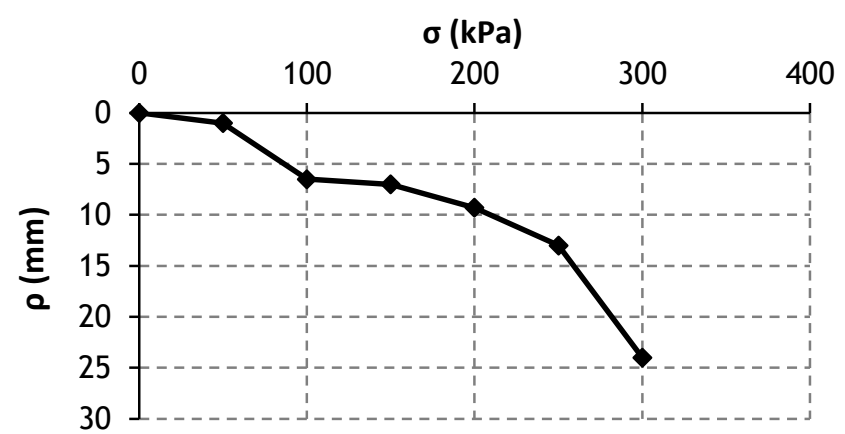

FIGURA 15: Curva Tensão x Recalque para cenário 3.

FONTE: Elaborada pelas autoras (2015).

Além da curva tensão-recalque, a planilha também fornece os histogramas comparando as tensões admissíveis para os métodos teóricos e semiempíricos com o valor obtido a partir da prova de carga, expostos nas Figuras 16a e 16b.
De modo geral, tanto os métodos teóricos como os métodos semiempíricos subestimam as tensões admissíveis, sendo o método de Teixeira aquele que apresenta menor variação, aproximadamente $63 \%$.

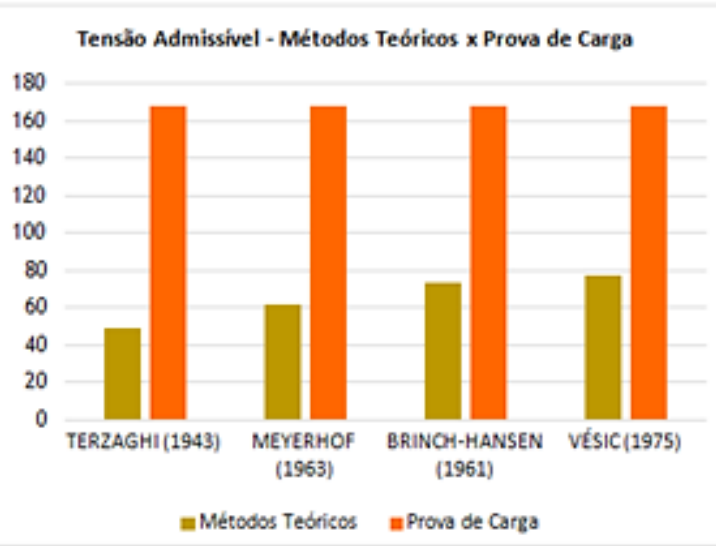

[a]

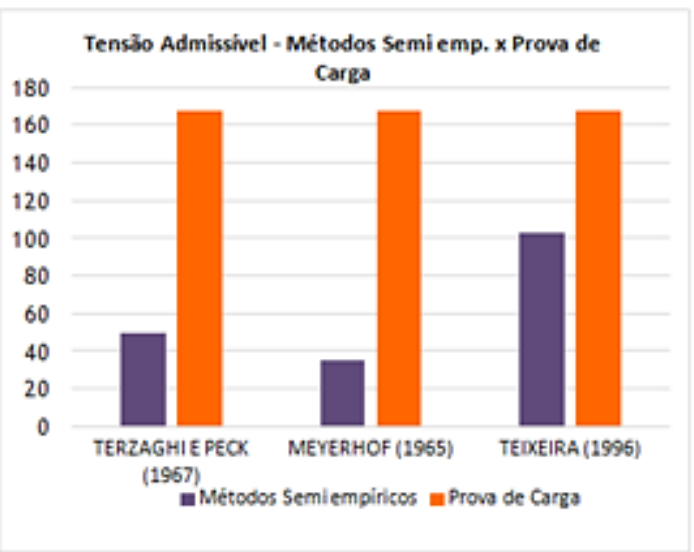

[b]

FIGURA 16: [a] Tensão admissível métodos teóricos $x$ prova de carga [b] Tensão admissível métodos semiempíricos $x$ prova de carga.

FONTE: Elaborada pelas autoras (2015). 


\section{CONSIDERAÇÕES FINAIS}

Os resultados demonstram que a ferramenta proposta neste trabalho determina a capacidade de carga e a tensão admissível para sapata com base quadrada, retangular ou circular, considerando a variação do nível freático e os três tipos de rupturas, e também exibe graficamente a comparação entre os valores obtidos para os métodos teóricos, semiempíricos e através do ensaio de placa.

As principais vantagens são: dispensa o uso de tabelas e ábacos vinculadas aos métodos teóricos, uniformizando os resultados obtidos; realiza o cálculo em um tempo mais curto do que se fossem realizados manualmente; permite simular diferentes cenários para uma mesma situação; pode ser aplicada quando se tem apenas uma sondagem a percussão ou também quando é realizado o ensaio de placa.

É importante salientar que a planilha pode ser usada tanto para fins acadêmicos como profissionais, porém a interpretação dos resultados deve ser feita pelo usuário, sendo necessário que o mesmo tenha conhecimento prévio sobre os métodos empregados para determinar a capacidade de carga e a tensão admissível do solo.

As autoras disponibilizam a planilha gratuitamente desde que solicite através dos contatos presentes nesse artigo.

\section{REFERÊNCIAS BIBLIOGRÁFICAS}

ASSOCIAÇÃO BRASILEIRA DE NORMAS TÉCNICAS, NBR 6122: Projeto e execução de fundações. Rio de Janeiro, 2010.

BOWLES, J. E. Foundation Analysis and Design. $5^{\text {th }}$ ed. Singapura: McGraw-Hill, 1997.

CARDOSO, A. F. C. Desenvolvimento de um programa de cálculo de sapatas de betão armado. Tese (Mestrado em Engenharia Civil) - Universidade de Aveiro. Aveiro,Portugal, 2011, 102 p.

CARVALHO, F. V. M. Otimização dos custos dos projetos de estaqueamento através de uma planilha de cálculo eletrônica de fundações profundas. Tese (Mestrado em Projeto de Estruturas) - Escola Politécnica, Universidade Federal do Rio de Janeiro. Rio de Janeiro, RJ, 2014, 126 p.
CINTRA, J. C. A.; AOKI, N.; ALBIERO, J. H. Fundações diretas: projeto geotécnico. São Paulo, Oficina de Textos, 2011.

CODUTO, D. P. Foundation Design: principles and practices. 2nd ed. Upper Saddle River, Prentice Hall, 2001.

DAS, B. M. Fundamentos de engenharia geotécnica. Tradução de All Tasks; Revisão Técnica de P. L. A. Barros. São Paulo, Thomson Learning, 2007.

FERREIRA, T. R.; DELALIBERA, R. G.; SILVA, W. A. Rotina computacional para a previsão da capacidade de carga em estacas. Revista Eletrônica de Engenharia Civil. Vol. 8 - n 3 - jun - Catalão/GO, 2014, 38-50 p.

HACHICH, W. et al. Fundações: teoria e prática. 2. ed. São Paulo, Pini, 1998.

HANSEN, J. B. A general formula for bearing capacity. Danish Geotechnical Institute, n. 11, 1961, 10 p.

MEDEIROS, P. M. Avaliação da previsão do comportamento geotécnico de fundações superficiais assentes em subsolos arenosos de baixa compacidade em fortaleza a partir de ensaios de placa. Tese (Mestrado em Engenharia Civil na área de Geotecnia) Universidade Federal do Ceará. Fortaleza, CE, 2013, 175p.

MEYERHOF, G. G. Some recent research on the bearing capacity of foundations, Vol. $1-n .1-1963,16-22$ p.

MEYERHOF, G. G. Shalow foundations. Journal of Soil Mechanics and Foundations Division ASCE, Vol. 91, n. 2, 1965, 21-31 p.

NOGUCHI, L. T. Análise da capacidade de carga de fundação por sapatas executadas na cidade de São Caetano do Sul/SP. Tese (Mestrado em Engenharia Civil na área de Geotecnia) - Faculdade de Engenharia Civil, Arquitetura e Urbanismo, Universidade Estadual de Campinas. Campinas,SP, 2012, 184 p.

TEIXEIRA, A. H. Projeto e execução de fundações. Seminário de Engenharia de Fundações Especiais e Geotecnia, 3. Anais... Vol. 1, São Paulo, 1996, 33-50p.

TERZAGHI, K. Theoretical soil mechanics. New York, John Wiley \& Sons, Inc, 1943.

TERZAGHI, K.; PECK, R. B. Soil mechanics in engineering practice. 2nd ed. New York, J. Wiley, 1967, 729 p.

VAN DER VEEN, C. The bearing capacity of a pile. Proc. 3rd Int. Conf. Soil Mech. Found. Engrg. Vol. 2, Zurich, 1953, 94-90p.

VÉSIC, A. S. Bearing capacity of shallow foundations. In: H. F. Winterkorn; H. Y. Fang (Eds.); New York: Van Nostrand Reinhold Co., 1975.

VELLOSO, D. A.; LOPES, F. R. Fundações: critérios de projeto, investigação do subsolo, fundações superficiais, fundações profundas. São Paulo, Oficina de Textos, 2010. 